\title{
Hearing Health in Agricultural Aviation Pilots from Cindacta II Wearing Earplugs and a Helmet
}

\author{
Vinicius Ribas Fonseca ${ }^{1,2}$ Bianca Simone Zeigelboim ${ }^{3}$ Adriana Bender Moreira Lacerda ${ }^{4}$ \\ Angela Ribas ${ }^{3,4}$ Guilherme Spanhol ${ }^{5}$
}

${ }^{1}$ Department of Otorhinolaryngology, Hospital da Cruz Vermelha, Curitiba, Paraná, Brazil

2 Otorhinolaryngology Course, Universidade Positivo, Universidade Tuiuti do Paraná, Curitiba, Paraná, Brazil

${ }^{3}$ Communication Disorders, Universidade Tuiuti do Paraná, Curitiba, Brazil

${ }^{4} \mathrm{MSc}$ and $\mathrm{PhD}$ in Communication Disorders, Universidade Tuiuti do Paraná, Curitiba, Paraná, Brazil

${ }^{5}$ Centro de Estudos Otorrinolaringológicos Lauro Grein Filho-Hospital da Cruz Vermelha, Curitiba, Paraná, Brazil

Address for correspondence Vinicius Ribas Fonseca, PhD, Department of Otorhinolaryngology, Otorrinos-Hospital da Cruz Vermelha, R. Vicente Machado, 1239 UEM-Sala 11, Curitiba, Paraná 80420-011, Brazil (e-mail: vribasfonseca@gmail.com).

Int Arch Otorhinolaryngol 2016;20:105-108.

\begin{abstract}
Keywords

- noise-induced hearing loss

- aviation

- agriculture

Introduction Agricultural aviation pilots, exposed daily to intense vibration and noise, are likely to develop noise-induced hearing loss (NIHL).

Objectives The aim of this study was to investigate the presence of audiograms consistent with $\mathrm{NIHL}$ in agricultural aviation pilots who use earplugs and helmets.

Methods We conducted a cross-sectional cohort and observational study. The data were taken from the medical records and audiograms of 94 pilots.

Results NIHL was identified in $9.5 \%$ of individuals with hearing loss by audiograms at $3,000,4,000$, or $6,000 \mathrm{~Hz}$. Normal audiograms were observed in $46.8 \%$ of pilots surveyed. Bilateral hearing loss was more frequent than unilateral hearing loss, occurring in $64.8 \%$ of cases.

Conclusion Although there was a low incidence of audiograms compatible with NIHL in the records of the pilots examined, the disorder still occurs despite the doubled use of individual hearing protection equipment (helmets and earplugs) for agricultural aviation pilots. Nevertheless, even with the use of earplugs and helmets as noise protectors, the data showed that agricultural pilots suffer inner ear damage caused by occupational noise. Prevention and periodic audiologic evaluations must be conducted in noiseexposed occupational groups.
\end{abstract}

\section{Introduction}

Noise-induced hearing loss (NIHL) is one of the most common diseases related to the work around the world and is a grievance in various work areas, such as steel work; metal fabrication; printers; the textile, paper, and cardboard industries; glazing; and air travel, among others. ${ }^{1}$ It is estimated that $25 \%$ of workers exposed to noise have

received

February 18, 2015

accepted

March 9, 2015

published online

May 7, 2015 some degree of NIHL. In addition, the problem ranks second among hypoacusis, only surpassed by presbycusis. ${ }^{1,2}$ The national epidemiologic data are scarce and refer only to certain fields of activity. ${ }^{3}$ This lack of data reinforces the importance of reporting cases, which raises awareness of the problem and permits the necessary prevention and assistance. 
Risk factors for NIHL can be classified as environmental risk factors, involving chemical, biologic, and physical agents (vibration and noise); metabolic risk factors, such as diabetes mellitus, renal and thyroid dysfunction, hypercoagulation, and dyslipidemia; and medical and genetic factors. ${ }^{1}$

The diagnosis of NIHL and its differentiation from other types of hearing loss (HL) tend to be easier in situations where the physician has access to the patient's history of exposure to noise and other ototoxic agents throughout his working life, with audiometric records of moments of normal hearing and at the start of the HL. ${ }^{4}$

Agricultural aviation pilots are exposed to noise during work that may occur for long periods, daily and weekly. The noise intensity can reach sound pressure levels above 100 $\mathrm{dB} .{ }^{1}$ This exposure, coupled with other risk factors (such as vibration, ototoxic agents, personal bias), can cause irreparable hearing damage. These risk factors could cause degeneration of hair cells in the organ of Corti and the recruitment phenomenon. As a result, patients exposed to these factors have a higher chance for communication impairment and NIHL. ${ }^{1,2}$

In the United States, the Occupational Safety and Health Administration creates standards and guidelines for noise exposure to protect workers. All employees who are exposed to more noise than $85 \mathrm{~dB}$ must participate in a program for the prevention of $\mathrm{HL}$ and the use of personal protection equipment. In addition, the Ministry of Health standards of Brazil limit workers' exposure to noise as follows: if the weighted average of the noise level is $90 \mathrm{~dB}$, the worker may be exposed for up to 8 hours; if the intensity is $95 \mathrm{~dB}$, for only 4 hours; and at $100 \mathrm{~dB}$, for only 2 hours (-Table $\mathbf{1}){ }^{4}$

The objective of this study was to verify the presence of audiograms compatible with NIHL in agricultural civil aviation pilots from CINDACTA II who wear earplugs and helmets.

\section{Methods}

This research is a cross-sectional cohort, observational study, and the subjects of the study were agricultural aviation pilots. Charts were analyzed of 94 agricultural aircraft pilots who attended the health inspection for the renewal of their Certificate of Physical Fitness in 2010. This study was reviewed and approved by the Research Ethics Committee, with protocol number 061/2011.

We included 94 occupational records of agricultural aircraft pilots (of the 123 records evaluated). Subjects were men, age 40 to 65 , with over 2,000 hours of flight time. Exclusion criteria were those pilots with HL prior to initial audiometry and chronic diseases that potentially cause HL, pilots who were exposed to nonoccupational noise, pilots who did not wear protective equipment when handling pesticides, and pilots who did not use earplugs and helmets.

All subjects underwent 14 hours of auditory rest before performing audiometric tests. Audiograms showing a notch at $3,000,4,000$ and/or $6,000 \mathrm{~Hz}$, with recovery at $8,000 \mathrm{~Hz}$, were classified as suggestive of NIHL. ${ }^{5}$

The data were compared with the medical literature and analyzed statistically using the chi-square test with Yates
Table 1 Tolerance limits for continuous or intermittent noise

\begin{tabular}{|l|l|}
\hline Noise level $(\mathrm{dB})$ & Maximum exposure permitted \\
\hline 85 & $8 \mathrm{~h}$ \\
\hline 86 & $7 \mathrm{~h}$ \\
\hline 87 & $6 \mathrm{~h}$ \\
\hline 88 & $5 \mathrm{~h}$ \\
\hline 89 & $4 \mathrm{~h} 30$ min \\
\hline 90 & $4 \mathrm{~h}$ \\
\hline 91 & $3 \mathrm{~h} 30$ min \\
\hline 92 & $3 \mathrm{~h}$ \\
\hline 93 & $2 \mathrm{~h} 30$ min \\
\hline 94 & $2 \mathrm{~h}$ \\
\hline 95 & $1 \mathrm{~h} 45$ min \\
\hline 98 & $1 \mathrm{~h} 15$ min \\
\hline 100 & $1 \mathrm{~h}$ \\
\hline 102 & $45 \mathrm{~min}$ \\
\hline 104 & $35 \mathrm{~min}$ \\
\hline 105 & $30 \mathrm{~min}$ \\
\hline 106 & $25 \mathrm{~min}$ \\
\hline 108 & $20 \mathrm{~min}$ \\
\hline 110 & $15 \mathrm{~min}$ \\
\hline 112 & $10 \mathrm{~min}$ \\
\hline 114 & $8 \mathrm{~min}$ \\
\hline 115 & $7 \mathrm{~min}$ \\
\hline
\end{tabular}

Source: Ministry of Health $2006^{2}$.

continuity correction. To determine the $p$ value (and the chi-square statistic), we used the STATISTICA system version 9.0 (Statsoft, USA).

\section{Results}

Audiometric evaluation analysis determined that hearing was within normal limits in 44 individuals (46.8\%), and 50 individuals (53.2\%) had altered audiometry (-Table 2 ). Of these, we found that the vast majority (64.8\%) had bilateral HL (-Fig. 1) and that $18 \%$ had notched results in 3,000, 4,000, and/or 6,000 $\mathrm{Hz}$ and $8,000 \mathrm{~Hz}$ in recovery (-Fig. 2), with 9.5\% of 94 audiometries assessed suggestive of NIHL $(p=0.009)$.

Table 2 Total of audiograms: normal, altered, and suggestive of $\mathrm{NIHL}$

\begin{tabular}{|c|c|c|c|}
\hline \multirow[t]{2}{*}{ Audiogram } & \multicolumn{3}{|c|}{ NIHL } \\
\hline & Yes & No & Total \\
\hline Normal & 0 & 44 & 44 \\
\hline Altered & 9 & 41 & 50 \\
\hline Total & 9 & 85 & 94 \\
\hline
\end{tabular}

Abbreviation: NIHL, noise-induced hearing loss. 


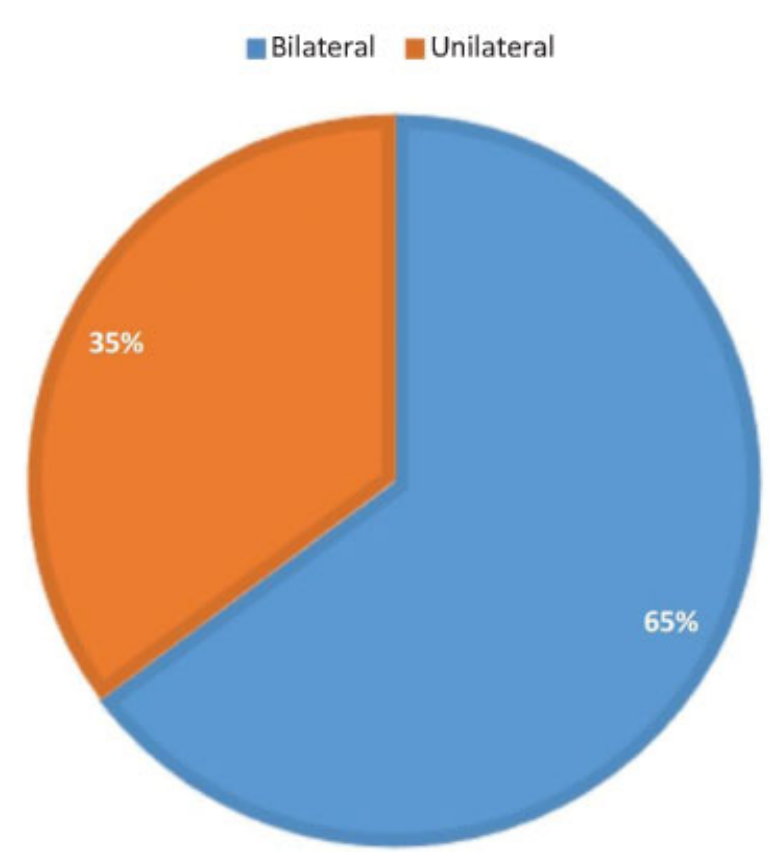

Fig. 1 Cases for unilateral or bilateral in audiograms with alterations.

The age and flight hours of patients with NIHL varied, and no relationship was found between the two with NIHL. A minimum of three audiometries, a maximum of five, and average three were done for each pilot under evaluation. The pilots were followed for up to 5 years, with a minimum of 1.5 years and an average of 3 years.

Audiometric signs of NIHL occurred within 2 years in the pilots' charts. Other types of HL occurred after 2 years of normal audiometry. Only bilateral HL was found in the audiometries suggestive of NIHL. Seventy-three percent of the other causes of HL were bilateral.

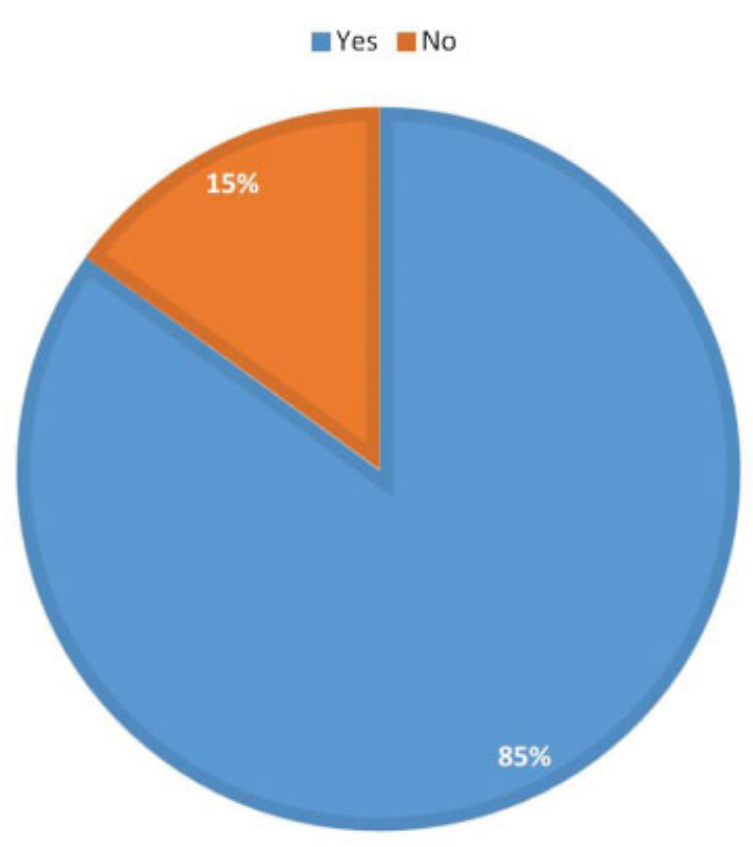

Fig. 2 Cases suggestive of NIHL in audiograms with alterations.

\section{Discussion}

This study is limited by the shortage of literature and international studies related to NIHL and agricultural aviation. Previous studies had mixed results in the evaluation of hearing health for aircraft pilots. The range of results comes from the fact that each study used different sample sizes, evaluation techniques, and lines of work, as well as assessed exposure to noise in various types of aircraft. ${ }^{6-8}$

In addition to these limitations, retention of the pilot's license depended on the pilot's responses, which may have influenced the completion of the occupational health forms related to the use of personal protective equipment such as earplugs and helmets, because every airman responded positively to the use of this equipment.

The difference in results of other studies can be explained in part by the correct use of personal hearing protection. All individuals in this research reported used protection (earplugs and helmet) during working hours. This shows that they are receiving adequate information and accepting the preventive measures. In the study by Foltz et al, $4.9 \%$ did not use such protection. The nonuse of personal hearing protection was relevant in the study of Silva et al, in which $64.5 \%$ of subjects did not use proper hearing protection. ${ }^{3,7}$

In Brazil, Regulatory Norm number 15 (NR-15) of the Ordinance MTb 3.214/1978 establishes the limits of the continuous noise exposure, as shown in - Table 1. ${ }^{2}$ Every case of NIHL is subject to compulsory notification by the national health system (Sistema Único de Saúde, SUS), according to the GM/MS Ordinance parameter in number 777 of 28 April 2004, in addition to requiring that occurrences be reported to Social Security, through a Job Accident Report (CAT from Portuguese). ${ }^{2}$

In the classification of audiometry, $53.2 \%$ of the individuals had some HL, a number greater than found in studies by Silva et al (38.1\%), Foltz et al (31.7\%), and Jaruchinda et al $(32.4 \%)^{3,7,9}$

Per the criteria from the American College of Occupational and Environmental Medicine, ${ }^{5}$ which cites the first NIHL sign as being a notch on the audiogram at 3,000,4,000, and/or $6,000 \mathrm{~Hz}$ and recovery at $8,000 \mathrm{~Hz}$, we found that $9.5 \%$ of the study population had HL suggestive of NIHL-a smaller number that that found in the study by Foltz et al, in which $29.3 \%$ of agricultural pilots showed these characteristics. ${ }^{7}$

After onset, changes in hearing thresholds have no potential for recovery. Therefore, there is not treatment yet for NIHL. Prevention and monitoring of the progression of HL through periodic hearing assessments are the strategies to be adopted. Preventive measures for airmen and crews to other activities are related to the control of noise, such as exposure control measures at the source, the area, and the individual (earplugs and helmets), with the proper selection of a hearing protector as key. In addition to these measures, there are organizational measures, such as working hour reductions, the establishment of breaks, and changes in work functions. The rate of progression of $\mathrm{HL}$ determines the effectiveness of the protection measures adopted and the need to apply others. ${ }^{2,6}$ Once the exposure stops, there will be no progression of HL. ${ }^{1}$ 
It is important to clarify that NIHL does not cause incapacity at work; however, it can cause limitations in performing various tasks. Each case must be assessed in relation to the difficulties presented to guide the rehabilitation and address the adequacy of the work environment. ${ }^{2}$

In the present study, a large group of subjects (43.7\%) had presence of HL with other audiometric characteristics (53.2\%) not suggestive of NIHL. Exposure to other risk factors and the older age group (40 to 65) may explain this finding. Exposure to pesticides, which are causal agents that cannot generate $\mathrm{HL}$, regardless of exposure to noise, can be one of these factors that interact with noise and enhance its effect on hearing, ${ }^{1,2,7}$ suggesting that these individuals may have HL due to this causative agent. This does not exclude presbycusis, organic, metabolic, pharmacologic, and/or genetic agents as potential causes of the HL presented.

In this study, there was a predominance of bilateral HL (64.8\%) over unilateral (35.2\%). Silva et al reported a unilateral HL prevalence. $^{3}$

The age and flight hours of patients with NIHL varied, with no relationship found between the two. However, following the natural history of the disease, pilots with longer work histories and exposure to noise demonstrated a worsening of the problem. ${ }^{3}$

With this study, we observed that agricultural aviators suffer from the effects caused by noise. Although there is full awareness by the airmen on the use of personal hearing protection, HL exists in the sample. The results suggest that these individuals have NIHL prevalence lower than rates reported in the literature.

Although the number of pilots with NIHL in the sample was not high, preventive measures such as individual hearing protection and noise exposure control should be encouraged in all exposed occupational groups, as well as the monitoring of the progression of HL through periodic hearing assessments. A survey aimed at laboratory tests and a survey of protection measures from exposure to pesticides must be performed in the present study group.

\section{Conclusion}

After this study, we can conclude that:

1. Although there were low incidences of audiograms compatible with NIHL in the records of the pilots examined, the disorder still occurs despite the doubled use of individual hearing protection equipment (helmets and earplugs) for agricultural aviation pilots.

2. Even with the use of personal hearing protection equipment in agricultural aviation pilots, HL with audiometric patterns not compatible with NIHL occurred in half of the pilots' medical charts and may point to the influence of other causal factors like contact with pesticides.

\section{References}

1 Ministério da Saúde. Secretaria de Atenção à Saúde. Departamento de Ações Programáticas Estratégicas. Doenças relacionadas ao trabalho. Brasília, Brazil: Editora do Ministério da Saúde; 2001

2 Ministério da Saúde. Secretaria de Atenção à Saúde. Departamento de Ações Programáticas Estratégicas. Perda auditiva induzida por ruído (Pair). Brasília, Brazil: Editora do Ministério da Saúde; 2006

3 Silva AP, Costa EA, Rodrigues SMM, Souza HLR, Massafera VG. Avaliação do perfil auditivo de militares de um quartel do Exército Brasileiro. Braz J Otorhinolaryngol 2004;70(3):344-350

4 Weber PC. Evaluation of hearing loss in adults. 2011. Available at: http://www.uptodate.com/contents/evaluation-of-hearing-lossin-adults? source=see_link. Accessed May 1, 2011

5 Acoeme Evidence Based Statement. Noise induced hearing loss. J Occup Environ Med 2003;45(6):106-108

6 Ribeiro AMD, Câmara VdeM. Hearing loss by continuous exposure to high sound pressure among maintenance workers at a Brazilian Air Force helicopters unity. Cad Saude Publica 2006;22(6): 1217-1224

7 Foltz L, Soares CD, Reichembach MAK. Perfil audiológico de pilotos agrícolas. Int Arch Otorhinolaryngol 2010;14(3):322-330

8 Lindgren T, Wieslander G, Dammstrom BG, Norback D. Hearing status among commercial pilots in a Swedish airline company. Int J Audiol 2008;47(8):515-519

9 Jaruchinda P, Thongdeetae T, Panichkul S, Hanchumpol P. Prevalence and an analysis of noise-induced hearing loss in army helicopter pilots and aircraft mechanics. J Med Assoc Thai 2005; 88(3, Suppl 3):S232-S239 